\title{
When valve-in-valve implantation is not sufficient: Bioprosthetic Russian dolls
}

\author{
Elaine E. Tseng, MD
}

\author{
From the Department of Surgery, University of California at San Francisco Medical Center (UCSF), and the San \\ Francisco Veterans Affairs Medical Center (SFVAMC), San Francisco, Calif. \\ Disclosures: Author has nothing to disclose with regard to commercial support. \\ Received for publication March 31, 2016; accepted for publication April 1, 2016; available ahead of print April \\ $26,2016$. \\ Address for reprints: Elaine E. Tseng, MD, Division of Cardiothoracic Surgery, UCSF Medical Center, 500 Par- \\ nassus Ave, Suite W405, Box 0118, San Francisco, CA 94143-0118 (E-mail: elaine.tseng@ucsf.edu). \\ J Thorac Cardiovasc Surg 2016;152:624-5 \\ 0022-5223/\$0.00 \\ Published by Elsevier Inc. on behalf of The American Association for Thoracic Surgery \\ http://dx.doi.org/10.1016/j.jtcvs.2016.04.018
}

The report by Leung Wai Sang and colleagues ${ }^{1}$ in this issue of The Journal on valve-in-valve-in-valve replacement describes a successful short-term clinical result for a challenging future problem. Nationally, bioprostheses are increasingly used in preference to mechanical valves in surgical aortic valve replacement (SAVR), particularly in younger populations, because of patient preference and transcatheter aortic valve replacement (TAVR) with the idea of future valve-in-valve (VIV) implantation. ${ }^{2}$ Because younger age at initial surgery carries greater likelihood of valve degeneration, structural valve deterioration (SVD) will become more prevalent. ${ }^{3}$ Although reoperative surgical aortic valve replacement carries a low mortality $(4.6 \%)$ among patients from Society of Thoracic Surgeons database (average age 66 years), ${ }^{4}$ VIV has been used in older patients (average age 78 years) with an acceptable 30-day mortality of $7.6 \% 5$ but can lead to suboptimal results from elevated gradients.

The first challenge in determining appropriateness of VIV is whether elevated gradients are caused by patientprosthesis mismatch (PPM) or SVD. PPM cannot be corrected but may be worsened by $\mathrm{VIV}^{6}$ and is best treated with reoperation if possible.

The second challenge is whether SVD from stenosis is related to subclinical leaflet thrombosis, recently reported for TAVR. ${ }^{7}$ Reduced leaflet motion was demonstrated by computed tomography without short-term consequences by echocardiography; however, such thrombosis may eventually lead to leaflet stiffening and elevated gradients with clinical SVD. Anticoagulation reduced thrombus formation. VIV may be at greater risk for thrombosis than either TAVR or surgical aortic valve replacement, since stasis predisposes to clotting. VIV displaces bioprosthetic leaflets to their stent, creating cylindrical wall within which TAVR sits. TAVR itself has a stent base covered with Dacron polyester fabric and leaflets enclosed within a circumferential stent. Sinus blood flow cannot immediately wash over TAVR leaflets. Instead, blood flow must traverse past a wall of surgical bioprosthetic leaflets and through open

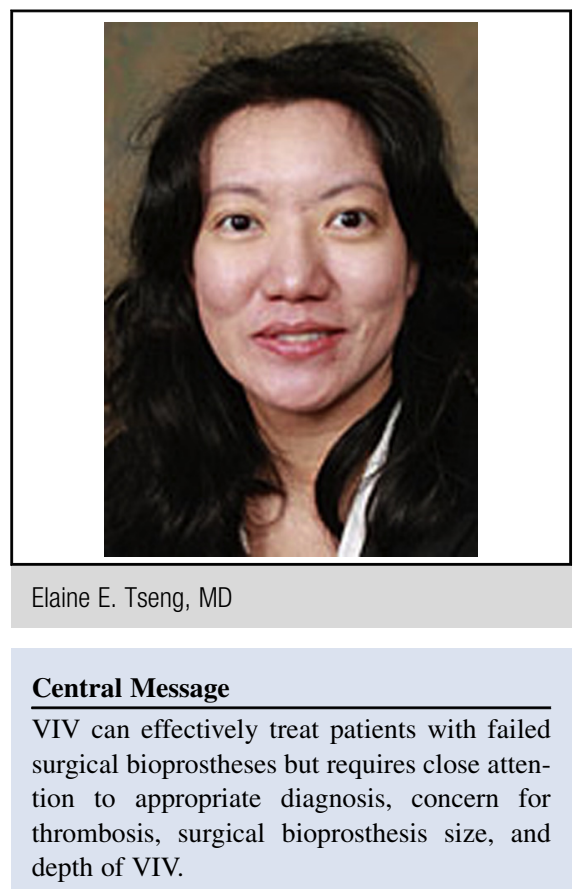

See Article page 622

stent TAVR cells to reach the leaflets; meanwhile, the TAVR base enclosed by the Dacron fabric without interstices prevents blood egress. As such, stasis is likely more with VIV, and patients undergoing VIV should be considered for anticoagulation to prevent future thrombosis, restricted leaflet motion, and potential early SVD. In the patient reported on by Leung Wai Sang and colleagues, whether initiation of a trial of anticoagulation late when SVD was diagnosed could have improved leaflet mobility is unknown but worth debating.

The third challenge relates to surgical bioprosthesis size, where smaller size leads to greater likelihood of development of VIV PPM. ${ }^{8}$ My own group previously demonstrated the inadequacy of gradient reduction in small-sized surgical bioprostheses $^{9}$ and the potential to improve gradients with either smaller 20-mm TAVR ${ }^{10}$ or supravalvular ${ }^{11}$ VIV placement. In the case report of Leung Wai Sang and colleagues, ${ }^{1}$ the use of a 20-mm Sapien XT (Edwards Lifesciences Corporation, Irvine, Calif) or supra-annular 23-mm CoreValve (Medtronic, Dublin, Ireland) for the initial VIV procedure might have potentially prevented the second VIV requirement. Nonetheless, a successful clinical result was achieved with a high CoreValve valve-in-valve-in-valve implantation 
supravalvularly, to maximize inflow within surgical bioprosthesis and VIV implants and situate TAVR leaflets above previous implants. ${ }^{6,11}$

Although the short-term results were acceptable, longerterm follow-up is necessary to determine whether this Russian Doll VIV implant will maintain acceptable, though not ideal, gradients. In summary, VIV implantation can effectively treat patients with failed surgical bioprostheses who are at high risk or not operative candidates, but it requires close attention to appropriate diagnosis, concern for reduced leaflet motion with potential for early SVD, surgical bioprosthesis size to avoid PPM, and depth of VIV to optimize hemodynamics.

\section{References}

1. Leung Wai Sang S, Giri J, Vallabhajosyula P. Transfemoral transcatheter valvein-valve-in-valve replacement. J Thorac Cardiovasc Surg. 2016;152:622-3.

2. Isaacs AJ, Shuhaiber J, Salemi A, Isom OW, Sedrakyan A. National trends in utilization and in-hospital outcomes of mechanical versus bioprosthetic aortic valve replacements. J Thorac Cardiovasc Surg. 2015;149:1262-9.e3.

3. Rahimtoola SH. Choice of prosthetic heart valve in adults an update. J Am Coll Cardiol. 2010;55:2413-26.
4. Kaneko T, Vassileva CM, Englum B, Kim S, Yammine M, Brennan M, et al. Contemporary outcomes of repeat aortic valve replacement: a benchmark for transcatheter valve-in-valve procedures. Ann Thorac Surg. 2015;100:1298-304; discussion 1304.

5. Dvir D, Webb JG, Bleiziffer S, Pasic M, Waksman R, Kodali S, et al. Transcatheter aortic valve implantation in failed bioprosthetic surgical valves. JAMA. 2014;312:162-70.

6. Dvir D. Treatment of small surgical valves: clinical considerations for achieving optimal results in valve-in-valve procedures. JACC Cardiovasc Interv. 2015;8: 2034-6.

7. Makkar RR, Fontana G, Jilaihawi H, Chakravarty T, Kofoed KF, de Backer O, et al. Possible subclinical leaflet thrombosis in bioprosthetic aortic valves. $N$ Engl J Med. 2015;373:2015-24.

8. Azadani AN, Jaussaud N, Matthews PB, Chuter TA, Ge L, Guy TS, et al. Aortic valve-in-valve implantation: impact of transcatheter-bioprosthesis size mismatch. J Heart Valve Dis. 2009;18:367-73.

9. Azadani AN, Jaussaud N, Matthews PB, Ge L, Chuter TA, Tseng EE. Transcatheter aortic valves inadequately relieve stenosis in small degenerated bioprostheses. Interact Cardiovasc Thorac Surg. 2010;11:70-7.

10. Azadani AN, Jaussaud N, Ge L, Chitsaz S, Chuter TA, Tseng EE. Valve-in-valve hemodynamics of 20-mm transcatheter aortic valves in small bioprostheses. Ann Thorac Surg. 2011;92:548-55.

11. Azadani AN, Jaussaud N, Matthews PB, Ge L, Guy TS, Chuter TA, et al. Valvein-valve implantation using a novel supravalvular transcatheter aortic valve: proof of concept. Ann Thorac Surg. 2009;88:1864-9. 